Revista de Derecho

de la Pontificia Universidad Católica de Valparaíso

LV (Valparaíso, Chile, 2do semestre de 2020)

[pp. 99-130 ]

\title{
SOBREENDEUDAMIENTO, SISTEMAS DE INFORMACIÓN CREDITICIA Y LA PROTECCIÓN DE LOS DATOS PERSONALES DEL CONSUMIDOR EN CHILE*
}

[Over Indebtedness, Credit Information Systems and Protection of

Consumer's Personal Data in Chile]

\author{
Sebastián Bozzo Hauri** \\ Universidad Autónoma de Chile
}

\begin{abstract}
Resumen
El fenómeno del sobreendeudamiento requiere de mecanismos eficaces para prevenirlo, resultando fundamental la existencia de sistemas de información crediticia que permitan al proveedor financiero estudiar el comportamiento de pago del consumidor. El sistema actual no provee información suficiente al acreedor, ya que no le permite tener acceso a información positiva. De esta manera, el presente trabajo tiene como objetivo estudiar los sistemas de información crediticia en Chile, realizando un estudio de la legislación actual, proyectos de ley presentados y sistemas comparados. El propósito así es entregar un análisis que permita avanzar hacia un modelo que compatibilice la entrega adecuada de información y la debida protección de los datos personales del consumidor, logrando un debido equilibrio de los distintos intereses en juego.
\end{abstract}

\begin{abstract}
The over indebtedness phenomenon requires effective mechanisms for it to be prevented, for which it is essential the existence of credit information systems that allow the financial provider to study the consumer's payment behavior. The current system does not provide enough information to the creditor, for not having access to actual positive information. Thus, this work aims to study the Chilean credit information systems, conducting a study of current legislation, bills submitted and compared legal systems. The purpose is to deliver an analysis that allows progress towards a model that makes compatible the delivery of information and due protection of consumer's personal data, achieving the proper balance of different interests at stake.
\end{abstract}

* Este trabajo forma parte del Proyecto Fondecyt Iniciación № 11180676 , Titulado "El fenómeno del sobreendeudamiento del consumidor en Chile y sus mecanismos de protección. Estudio a la luz del derecho europeo y español y los principios que lo inspiran”.

** Abogado, Magíster y Doctor en Derecho. Profesor de Derecho Civil Universidad Autónoma de Chile, Pedro de Valdivia 641, Providencia, Santiago, Chile. Correo electrónico: sebastian.bozzo@uautonoma.cl 
Palabras Clave

Sistemas de información crediticia sobreendeudamiento - préstamo responsable - protección de datos personales.
KEY WORDS

Credit information systems - over indebtedness - protection of personal data - responsible loan.

RECIBIDO el 11 de octubre de 2020 y ACEPTADO el 26 de marzo de 2021

\section{INTRODUCCIÓN}

El Informe de Endeudamiento realizado por la Comisión para el Mercado Financiero ${ }^{1}$ en 2016 expone que la deuda representativa de los deudores en Chile a junio de 2016 aumentó desde $\$ 1,55$ millones a $\$ 1,63$ millones, experimentando una variación de $0,7 \%$ real respecto a igual fecha del año anterior ${ }^{2}$. El Informe de 2017 advirtió un incremento en las cifras y señaló que los clientes bancarios con crédito de consumo tenían una deuda representativa que superaba los $\$ 2$ millones y los clientes con crédito hipotecario tenían una deuda representativa cercana a los $\$ 19,5$ millones ${ }^{3}$, mostrando un alza de 3,8\% nominal respecto a igual mes del año anterior ${ }^{4}$. El año 2018, la CMF observó un aumento en el nivel de deuda representativa un 10,1\% nominal y 7,3\% real entre junio de 2017 y junio de 2018. Así, la deuda mediana de consumo alcanzó los \$2,6 millones 5 .

Respecto del acceso al crédito, el informe de Endeudamiento a junio del 2019, las cifras señalan que un 49\% de la población tienen acceso a crédito (representado con un 24,9\% por medio de tarjetas de crédito bancarias, en el caso de los hombres y un $27,2 \%$ en el caso de las mujeres; con un $32,9 \%$ en tarjetas de crédito no bancarias, en el caso de los hombres y un $38,4 \%$ en el caso de las mujeres) ${ }^{6}$.

\footnotetext{
${ }^{1}$ En adelante CMF.
}

2 Superintendencia de Bancos e Instituciones Financieras, Informe de Endeudamiento de 2016, p. 3. Disponible [en línea]: https://www.sbif.cl/sbifweb3/ internet/archivos/DISCURSOS_11422.pdf.

${ }^{3}$ SERNAC, ¿Qué hacer si estás sobreendeudado?, Disponible [en línea]: https://www. sernac.cl/portal/618/w3-article-55112.html.

${ }^{4}$ Superintendencia de Bancos e Instituciones Financieras, Informe de Endeudamiento de 2017, pp. 8-9. Disponible [en línea]: https://www.sbif.cl/ sbifweb3/internet/archivos/publicacion_11891.pdf.

5 Superintendencia de Bancos e Instituciones Financieras, Informe de Endeudamiento de 2018, pp. 8-9. Disponible [en línea]: https://www.sbif.cl/ sbifweb3/internet/archivos/publicacion_12362.pdf.

${ }^{6}$ Superintendencia de Bancos a Instituciones Financieras, Informe de Endeudamiento de 2019. Disponible [en línea]: http://www.cmfchile.cl/portal/ estadisticas/606/articles-28149_recurso_1.pdf. 
En relación con los deudores bancarios, el informe de Endeudamiento de junio del 2019, elaborado por la CMF señala que los segmentos que exhiben mayores índices de morosidad e impago son los de menores ingresos; es decir, adultos mayores de 65 años y jóvenes menores de 30 años. Además, según indica el informe, en este segundo grupo se encuentran los deudores cuya carga financiera supera el $50 \%$ de su ingreso mensual ${ }^{7}$.

Para evitar el sobreendeudamiento es necesario la existencia de mecanismos que permitan consolidar la información crediticia de los deudores, y con ello, establecer un marco regulatorio que permita consagrar el principio denominado: "Préstamo Responsable", en virtud del cual es posible exigir a los bancos y financieras que otorguen créditos a sujetos que estén en condiciones de cumplir con el pago del préstamo ${ }^{8}$.

El nacimiento y desarrollo de este principio se debe por lo ineficiente que ha resultado la protección del consumidor. Esto en dos sentidos, el primero en el ámbito contractual, dado que el consumidor es inundado de información que no comprende, impidiéndole resguardar de manera efectiva su propio interés. El segundo, se refiere a evitar que el consumidor caiga en insolvencia, previniendo su sobreendeudamiento. Por lo anterior, la noción de préstamo responsable se enfoca no solo en el deber precontractual de entrega de información', sino en exigir a las entidades de crédito que evalúen de manera adecuada la solvencia del deudor ${ }^{10}$.

7 Superintendencia de Bancos e Instituciones Financieras, Informe de Endeudamiento de 2019, cit. (n. 6). En relación con la noción y causas del sobreendeudamiento ver Ruz LáRTIGA, Gonzalo, Nuevo derecho concursal chileno I y II, (Santiago, Thomson Reuters, 2017) p. 493, y Caballero Germain, Guillermo, Sobreendeudamiento y exoneración legal de los saldos insolutos en el procedimiento concursal del consumidor, en Revista Ius et Praxis, 24 (2018) 3, pp. 135-139.

${ }^{8}$ Bozzo Hauri, Sebastián, Sobreendeudamiento del consumidor en Chile: una revisión a la luz del derecho europeo, en Revista de Derecho (Valdivia) 33 (2020) 1, pp. 175-176. [https://doi.org/10.4067/S0718-09502020000100159]. GOLDENBERG SERRANO, Juan Luis, El sobreendeudamiento y los paradigmas del consumidor financiero responsable y del proveedor financiero profesional, en Revista Ius et Praxis, 26 (2020) 1, p. 4.

${ }^{9}$ Gallego Sánchez, Esperanza, La obligación de evaluar la solvencia del deudor: Consecuencias derivadas de su incumplimiento, ahora, en Prats AlBentosa, Lorenzo Cuena Casas, Matilde (coordinadores), Préstamo Responsable y Ficheros de Solvencia (Cizur Menor, Aranzadi Thomson Reuters, 2014) p. 207.

${ }^{10}$ Cuena Casas, Matilde, El Sobreendeudamiento privado como causa de la crisis financiera y su necesario enfoque multidisciplinar, ahora, en PrATs Albentosa, Lorenzo - Cuena Casas, Matilde (coordinadores), Préstamo Responsable y Ficheros de Solvencia (Cizur Menor, Aranzadi Thomson Reuters, 2014) p. 28. Además, como ha señalado Gallego Sánchez, Esperanza, cit. (n. 9) p. 223, la obligación de evaluar la solvencia no es el único deber que envuelve el principio de préstamo responsable, sino que 
En este sentido, los sistemas de información crediticia ${ }^{11}$ son útiles para prevenir el sobreendeudamiento, permitiendo a las entidades de crédito conocer el estado de solvencia del consumidor.

En lo sucesivo se denominarán SIC, el conjunto de ficheros y base de datos que suministran información acerca de la solvencia de personas físicas o jurídicas, o por decirlo con mayor precisión, la pluralidad de elementos, incluyendo a personas físicas o jurídicas, que están involucradas en el intercambio organizado de información a través de tecnologías avanzadas conforme a unos procedimientos previamente acordados, con el propósito de recopilar, elaborar, compartir y/o suministrar información sobre solvencia de particulares y empresarios. Así pues, estamos antes "sistemas" cuyo objeto es la generación y difusión de información, si bien de un tipo muy específico, que es la relativa a la solvencia o crédito de alguien ${ }^{12}$.

Así, los SIC son una parte esencial de la infraestructura financiera, pues permiten al consumidor tener acceso al financiamiento y por otra parte el desarrollo del sector financiero fomenta el poder productivo de las empresas y facilita la inclusión del sector informal en la economía formal.

Entre los SIC se puede distinguir entre negativos y positivos. Los primeros, dan cuenta del incumplimiento de las obligaciones dinerarias y los segundos entregan información relativa a su cumplimiento.

El acceso a la información contenida en estos ficheros posibilita que las entidades financieras conozcan y evalúen la situación del cliente con relación al cumplimiento de sus obligaciones. En este sentido, el comportamiento pasado facilita la predicción del comportamiento futuro ${ }^{13}$.

también le caben otros deberes al acreedor, como el deber de consejo o asistencia. Por ejemplo, en la Ley 16/2011 artículo 11 de Contrato de crédito al Consumo, se establece el deber de asistencia. Este deber obliga a la entidad, y, en su caso, los intermediarios de crédito, a facilitar al consumidor explicaciones adecuadas de forma individualizada para que éste pueda evaluar si el contrato de crédito propuesto se ajusta a sus intereses, a sus necesidades y a su situación financiera, si fuera preciso explicando la información precontractual, las características esenciales de los productos y los efectos específicos que pueden tener sobre el consumidor, incluidas las consecuencias en caso de impago por parte del mismo. En términos similares se establece en España en la Ley 2/2011 de 4 de marzo, artículo 29 de Economía Sostenible.

${ }^{11}$ En adelante SIC.

${ }^{12}$ Pascual Huerta, Pablo, Definición, funciones y estructura de los sistemas de información crediticia. El impacto del reglamento general de protección de datos de la Unión Europea, ahora, en CuEna CASAS, Matilde (directora), La prevención del Sobreendeudamiento Privado, Hacia un Préstamo y consumo responsable (Cizur Menor, Thomson Reuters Aranzadi, 2017) p. 121.

${ }^{13}$ Miller, Margaret, Credit Reporting Systems Around the Globe: The State of the Art in Public and Private Credit Registries, ahora, en Miller, Margaret (editor), 
Hasta ahora en Chile la única información existente respecto del cliente es aquella referida al incumplimiento de sus obligaciones, sin que exista información relacionada al cumplimiento.

De esta forma, es necesario que las instituciones financieras evalúen correctamente el estado de endeudamiento del consumidor. Para esto último, resulta fundamental tener la información completa, es decir no solo sus incumplimientos, sino que también aquellos créditos actuales del consumidor que no ha incumplido. Esto es importante, ya que hipotéticamente puede existir un consumidor que nunca haya incumplido con el pago de una deuda, pero dado su estado actual de endeudamiento puede incumplir futuros compromisos dinerarios que contraiga.

En este sentido, como hipótesis el trabajo postula que para consagrar en Chile el principio de préstamo responsable, es necesario construir un SIC mixto, es decir, que incluya información positiva y negativa del deudor ${ }^{14}$.

Así, el objetivo general es estudiar los sistemas de información crediticia en Chile, realizando un estudio de la legislación actual, proyectos de ley presentados y sistemas comparados. Todo esto con el propósito de entregar un análisis que permita avanzar hacia un modelo que compatibilice la entrega adecuada de información y la debida protección de los datos personales del consumidor, logrando un debido equilibrio de los distintos intereses en juego.

\section{REGÍMENES DE SISTEMAS DE INFORMACIÓN CREDITICIA}

Los SIC abordan un problema fundamental de los mercados crediticios: la información asimétrica entre deudores y acreedores, que puede llevar a selección adversa; es decir, entregar créditos a deudores que se encuentran sobreendeudados y, por ende, con posibilidades de caer en insolvencia.

Por consiguiente, la importancia de los sistemas de información crediticia juega un rol clave, permitiendo por una parte disminuir el riesgo financiero que significa el incumplimiento de las obligaciones por los deudores, y por otra, es una herramienta efectiva para fomentar el acceso al crédito ${ }^{15}$.

Credit Reporting Systems and the International Economy (Cambridge-Massachussets, MIT Press, 2003) pp. 35-36.

${ }^{14}$ Hernández Sampieri, Roberto, Fernández Collado, Carlos y Baptista Lucio, Pilar, Metodología de la Investigación (5a edición, Méjico, McGraw-Hill, 2013) pp. 25-26.

${ }^{15}$ Montes, Fredes, Sistemas de información crediticia. Principios generales y marco internacional, ahora, en Prats Albentosa, Lorenzo - Cuena Casas, Matilde (coordinadores), Préstamo Responsable y Ficheros de Solvencia (Cizur Menor, Aranzadi 


\section{Noción y tipos de sistemas}

Un sistema de información crediticia es una institución que recopila información de acreedores y de fuentes públicas disponibles sobre el historial crediticio de los prestatarios. Esta entidad recibe información sobre personas y pequeñas empresas relativa a créditos de las entidades que participan en el sistema, y luego la cruza con información relativa a sentencias judiciales y quiebras, compila esta información en un fichero común y luego elabora un informe crediticio que entrega a los usuarios del sistema ${ }^{16}$.

Se distinguen tres tipos de sistemas: registro consolidado de deudas; los bureaus de crédito y empresas de información comercial ${ }^{17}$.

El registro consolidado de deudas almacena datos de deudores de las entidades bancarias y financieras. El registro de deudas o también denominado central de riesgo ${ }^{18}$, están gestionadas por un ente regulador (bancos centrales o superintendencias financieras) y cuya principal función es compartir información de los deudores con el propósito de mantener la estabilidad financiera. De esta manera, el ente regulador puede exigir a las instituciones bancarias y financieras u otros actores relacionados, que informen sobre su cartera de crédito y de su morosidad ${ }^{19}$. Este tipo de registro cumple efectivamente su finalidad cuando todos los actores financieros, es decir, todos aquellos que conceden prestamos participan del registro ${ }^{20}$.

Thomson Reuters, 2014) p. 249. MAS BADIA, María Dolores, Los ficheros de solvencia patrimonial en la proyectada nueva Ley Orgánica de Protección de Datos de carácter personal. ¿Un avance o una oportunidad perdida?, en Actualidad Civil, 11 (2017) p. 3.

${ }^{16}$ Corporación Financiera Internacional, Sistemas de información crediticia. Guia informativa (Washington, 2006). Disponible [en línea]: http://documentos. bancomundial.org/curated/es/122091468177562819/Sistemas-de-informacioncrediticia-guia-informativa.

${ }^{17}$ Montes, Fredes, cit. (n. 13) p. 255.

${ }^{18}$ En España existe la Central de Información de Riesgos de Banco de España (CIRBE), que tiene como principal objetivo proporcionar información sobre el nivel de exposición por riesgo de crédito de las entidades financieras.

${ }^{19}$ Este tipo de ficheros pueden concentrar la siguiente información: la identificación del deudor y sus garantes, el monto original de la deuda y el monto pendiente y el tipo de crédito otorgado entre otros.

${ }^{20}$ En Chile se discute desde el año 2011 un proyecto de ley en la Cámara de Diputados Boletín (7886-03) que permitiría la creación de un registro consolidado de deudores. Actualmente en el caso de los créditos de consumo existen múltiples actores, sin que puedan estos acceder a un sistema de registro único de deudas que dé cuenta del verdadero estado de endeudamiento del consumidor. Sólo los bancos comparten información sobre el estado de solvencia de sus clientes, pero en ellos no participa el retail o casas comerciales. El mensaje del proyecto señala lo siguiente:

"El proyecto de ley propone un esquema que es orgánico con el sistema actualmente 
Por su parte los bureaus de crédito surgen como resultado del acuerdo voluntario de las partes de compartir información entre un grupo determinado de participantes con el objetivo de mitigar riesgos de incumplimiento de pago. En este sentido, se entiende por bureaus de crédito aquel modelo de intercambio de información crediticia cuyo objetivo principal es mejorar la calidad y disponibilidad de datos para que los acreedores tomen decisiones con más información ${ }^{21}$. Es habitual que estos sistemas de información crediticia sean controlados por privados, ya sean asociaciones privadas o compañías mercantiles, o bien bajo el control de organismos públicos, generalmente banco centrales o superintendencias ${ }^{22}$. De esta forma, se pueden distinguir bureaus de crédito privados como públicos.

En el caso de Chile sucede esto último, ya que es la antigua Superintendencia de Bancos e Instituciones Financieras, hoy Comisión de Mercado Financiero, quien tiene a su cargo el intercambio de información crediticia proporcionado por los bancos y demás instituciones financieras. Dicha

vigente, buscando consolidar en un solo organismo la recopilación de información comercial.

De esta forma, el proyecto propone crear un sistema oficial, en el que se registrarán, en los términos y condiciones que se establecen en el proyecto, todos los datos de obligaciones económicas. Este sistema tendrá como objetivo, en los términos señalados en el presente proyecto de ley, recopilar, consolidar y estandarizar la información sobre obligaciones económicas contraidas con todos los acreedores relevantes.

Para ello, los acreedores antes mencionados tendrán la obligación de informar al sistema las obligaciones económicas o crediticias que se describen en el proyecto, lo que incluye información de deuda morosa y también de deuda al día, ésta última con el consentimiento de los titulares, sentándose en el proyecto de ley las directrices y principios que deben regir la remisión de la información al sistema.

Elsistema deberá ordenar, sistematizar y filtrar la información a la que pueden acceder los usuarios y las empresas de distribución de información comercial, preocupándose que se respeten los derechos de los titulares de los datos, y siempre en la forma y condiciones permitidas por el proyecto de ley.

La administración del SOE será licitada por la entidad reguladora que se consagra en el proyecto de ley. El administrador, como responsable de la base de datos, se someterá a los principios de tratamiento de datos personales expresados en la Ley $N^{\circ} 19.628$, dentro de los que destacan el principio de legitimidad, exactitud, finalidad, proporcionalidad, transparencia, no discriminación y seguridad en el tratamiento de los datos personales. Además, deberá cumplir con una serie de requisitos para asegurar la continuidad y confiabilidad del sistema cuya observancia será fiscalizada por el regulador".

${ }^{21}$ Montes, Fredes, cit. (n. 15) p. 257.

${ }^{22}$ Pascual Huerta, Pablo, Los Ficheros de solvencia positivos. Una visión desde el derecho comparado, ahora, en Prats Albentosa, Lorenzo - Cuena Casas, Matilde (coordinadores), Préstamo Responsable y Ficheros de Solvencia (Cizur Menor, Aranzadi Thomson Reuters, 2014) p. 310. En el caso de Chile no existe control de un organismo público central. 
información se intercambia entre los propios reportantes y los titulares de dicha información.

La tercera categoría de sistema de información crediticia se encuentra conformada por las empresas de información comercial. Estas empresas se encargan de recopilar información de diferentes fuentes, ya sea de entidades financieras como créditos comerciales o de carácter mercantil, es decir, aquel que surge entre comerciantes. A diferencia de los bureaus de crédito, las empresas de información comercial se centran en entregar datos financieros de las empresas, sobre todo pequeñas y medianas empresas. De esta forma los usuarios de esta información pueden evaluar eficazmente la solvencia de una empresa, ya sea para conceder un préstamo o para entablar relaciones comerciales entre empresas.

En el caso de Chile, esta tercera categoría se confunde en ocasiones con los bureaus privados de crédito. No obstante, la esencia de los bureaus de crédito privado radica en el acuerdo voluntario entre los distintos actores del mercado financiero para intercambiar información, lo cual no sucede con las empresas de información comercial, ya que su origen no se encuentra en un acuerdo entre empresas.

\section{Principios generales}

El desarrollo de los principios generales que sustentan el SIC es producto del trabajo de distintos organismos internacionales. Así, por ejemplo, el año 2009 la Comisión Europea coordinó el trabajo de un grupo de expertos en historiales de crédito, con el fin de alcanzar cierta convergencia entre los distintos sistemas de información crediticia en el marco de la Unión Europea $^{23}$. De esta manera, el esfuerzo iniciado el año 2009 finaliza el año 2011 con la formulación de los principios generales de información credi-

${ }^{23}$ Comisión Europea. DG Mercado Interior y Servicios, Informe del Grupo de Expertos en Historia de Crédito (mayo 2009). Disponible [en línea]: https:// europa.eu/rapid/press-release_IP-08-1286_en.htm?locale=FR. También se puede ver como ejemplo la Iniciativa de Sistemas de Reporte de Préstamos Bancarios y Créditos del Hemisferio Occidental, http://www.whcri.org/index.html. Otros trabajos relevantes incluyen El Informe sobre los Sistemas de Información de Crédito y el Flujo Transfronterizo de Datos Crediticios realizado por el grupo de expertos coordinado por la Dirección General del Mercado Interior y Servicios de la Comisión Europea, el trabajo realizado por el Banco Central Europeo a través del Grupo de Trabajo de Registros de Crédito y la labor realizada por la Conferencia Internacional de autoridades de Protección de Datos y Privacidad. 
ticia ${ }^{24}$, con el objetivo de ser aplicados a nivel doméstico en todos aquellos países que cuenten con sistemas de información de crédito ${ }^{25}$.

El desarrollo del sector financiero fomenta el poder productivo de las empresas y facilita la inclusión del sector informal en la economía formal. Para el cumplimiento de esto último, es importante que los sistemas de información crediticia respondan a ciertos objetivos de política pública, permitiendo el desarrollo de concesión responsable de crédito en una economía, como base para un mercado crediticio fuerte y competitivo. De esta forma, los principios generales que informan a un correcto sistema de información crediticia debiesen considerar las siguientes áreas ${ }^{26}$ : datos, procesos, gobierno corporativo y gestión de riesgo, marco jurídico y reglamentario y flujo transfronterizos de datos.

Siguiendo los principios generales de información crediticia construidos por el Banco Mundial, se pueden identificar 5 grandes principios:

i) Datos: Los sistemas de información de crédito deberían disponer de suficientes datos, oportunos, precisos y pertinentes, incluyendo información positiva, recogidos de forma sistemática de todas las fuentes disponibles siempre y cuando éstas sean adecuadas y fiables, y deberían conservarlos durante un período de tiempo suficiente. Si los datos no son precisos se puede generar una distorsión de la realidad, repercutiendo en la denegación injustificada de créditos u obtención de éstos a un valor mayor. Inclusive puede repercutir en otras áreas como la laboral, ya que en muchos procesos de selección de puestos de trabajo se exige no tener antecedentes comerciales negativos ${ }^{27}$.

ii) Seguridad de datos y los sistemas: Los sistemas de información de crédito deben contar con normas estrictas de seguridad y fiabilidad y ser eficientes. Los datos tienen un valor porque constituye información valiosa para los distintos actores del mercado. En este sentido, su almacenamiento debe ser seguro para que éstos no se pierdan, destruyan o sean robados por terceros que busquen obtener un beneficio económico con su uso.

${ }^{24}$ La industria de información crediticia participó activamente en el desarrollo de los Principios Generales, representada por la Asociación de Información de crédito al Consumo como por la Asociación de Proveedores de Información de Crédito.

${ }^{25}$ Montes, Fredes, cit. (n. 15) p. 286.

${ }^{26}$ En esta parte seguiremos lo señalado por MonTes, Fredes, cit. (n. 13) p. 287 ss., que se basa en lo indicado por el BAnCo Mundial, General principles for credit reporting (Washington DC, 2011). Disponible [en línea]: http://documents. worldbank.org/curated/en/2011/09/16426885/general-principles-credit-reporting.

${ }^{27}$ En Chile la Ley 20.575 que estableció el principio de finalidad en el uso de datos personales, prohíbe exigir esta información en procesos de selección de personal, admisión preescolar, escolar o educación superior, atención médica de urgencia o postulación a un cargo público. 
iii) Gobierno corporativo y continuidad del servicio: Los mecanismos de gobierno corporativo de los proveedores de servicios y de los proveedores de datos deberían garantizar la responsabilidad, transparencia y eficacia en la gestión de los riesgos asociados con este sector de actividad, así como el acceso equitativo a la información por parte de los usuarios. Para asegurar lo anterior, es indispensable que se implementen mecanismos que garanticen una adecuada responsabilidad de sus directivos, incluyendo auditorías independientes y controles efectivos.

iv) Marco jurídico y regulatorio: El marco jurídico y normativo relativo a los sistemas de información crediticia debería ser claro, previsible, no discriminatorio, equilibrado y favorable a los derechos del consumidor y de los titulares de datos. El marco jurídico y normativo deberían incluir mecanismos eficaces, tanto judiciales como extrajudiciales, de resolución de litigios entre los participantes del servicio de información crediticia. Un marco jurídico debe resguardar los diferentes intereses envueltos, es decir, por un lado, el objetivo de tener acceso a la mayor cantidad de información posible y el interés de resguardar la privacidad de las personas.

v) Transferencia internacional de datos: El flujo transfronterizo de datos en materia de información crediticia debería facilitarse cuando sea pertinente siempre que se den los requisitos adecuados. En una sociedad cada vez más globalizada urge que ciertos instrumentos como lo son los sistemas de información de crédito consideren el traslado de las personas a otros países. Por consiguiente, es posible que dichas personas si bien tienen una nueva residencia, sigan utilizando los servicios financieros de entidades que pertenecen a su país de origen. De esta manera, la información financiera de un cliente debe abarcar su historial más allá del lugar en que haya residido los últimos años. Además, la transferencia internacional de datos promueve la integración económica y financiera entre países, puesto que permite un correcto análisis del estado de solvencia de un consumidor o empresa.

\section{Protección de los datos financieros en Chile y su regulación comparada}

El marco jurídico en Chile está conformado por el Decreto Supremo No 950 del Ministerio de Hacienda, publicado en el Diario Oficial el 28 de marzo del año 1928 y modificado la última vez el 25 de octubre del año 2006, la Ley 19.628 sobre protección de la vida privada y la Ley 20.575 que establece el principio de finalidad en el tratamiento de datos personales.

Toda esta regulación, como se expondrá a continuación, es insuficiente para obtener un correcto control, calidad y veracidad de los datos. Las normas de seguridad para proteger la integridad de la información, los plazos y formatos de envío por parte de los acreedores y los mecanismos de 
rectificación entre otras materias, son establecidos por los propios agentes del mercado y poco conocidos por el público.

Por otra parte, no existe una entidad especializada que supervise o monitoree el correcto funcionamiento de la industria ${ }^{28} \mathrm{y}$, en especial, el adecuado tratamiento de los datos que administran.

De esta manera, hoy nuestros consumidores no pueden recurrir a una instancia de como el SERNAC, para hacer valer sus derechos en esta materia. Ofrecer esta posibilidad, permitiría entre otras cosas, que el Servicio actúe como intermediario en la solución del conflicto, permitiendo evitar que el problema escale hasta sede jurisdiccional. Permitiendo además que el SERNAC eduque a los consumidores sobre los derechos que le asisten en materia de protección de datos de carácter económico.

a) Decreto $N^{o} 950$. El Decreto No 950 en su artículo $1^{\circ}$ señala que todas las oficinas de la República que en este artículo se expresen (notarios; juzgados civiles; conservadores de bienes raíces; las instituciones, empresas y organismos fiscales, semifiscales o de administración autónoma, que realicen actividades destinadas a promover el desarrollo económico del país; la asociación nacional de ahorro y préstamo y los bancos y sociedades financieras) deberán enviar nóminas en distintos plazos conforme a la naturaleza de la institución, las cuales deberán contener el nombre completo del deudor, Rol Único Tributario, su domicilio y el monto del servicio que estuviere debiendo. Por ejemplo, los notarios, deben enviar un listado de la nómina de las letras protestadas; lista de compraventas, remates y adjudicaciones de bienes raíces; lista de los mutuos hipotecarios; listas de las cancelaciones; convenios extrajudiciales entre comerciantes, etc.

El artículo $3^{\circ}$ entrega la responsabilidad a la Cámara de Comercio de Chile de publicar bajo su vigilancia y responsabilidad un boletín semanal que contenga los datos referidos en el artículo primero.

Se establece que el costo de la publicación será de su cargo, debiendo

\footnotetext{
${ }^{28}$ Hoy la industria está conformada por la Cámara de Comercio de Santiago, quien construye el Boletín de Información Comercial, publicando principalmente los protestos de documentos, además maneja y comercializa una base de datos llamada INFOCOM que contiene datos de cuotas morosas sin protestar reportados voluntariamente por el comercio, los bancos y otros acreedores. A su vez, desde la década de los ochenta, han comenzado a operar en Chile empresas de distribución de información comercial, como DICOM/Equifax, Data Business (filial de la Cámara de Comercio), SINACOFI (Filial de la Asociación de Bancos e Instituciones Financieras) y SIISA (de propiedad de TransUnión, uno de los tres Burós federales existentes en Estados Unidos de Norteamérica). Todas estas empresas mantienen contratos de licencia de uso con la Cámara de Comercio de Santiago para obtener los datos del Boletín de Información Comercial.
} 
distribuir entre las Cámaras de Comercio que tengan personalidad jurídica, tantos ejemplares como número de socios tenga cada una de ellas. Como compensación de este servicio, las Cámaras de Comercio indicadas y los bancos abonarán a la Cámara de Comercio de Chile la suma equivalente al número de ejemplares destinados a los socios de cada una de ellas.

Por su parte el artículo $4^{\circ}$ del referido Decreto establece que el Boletín de Informaciones Comerciales contendrá una Sección "Aclaraciones" en la que, sin costo alguno para los interesados, se insertarán extractos, permitiendo que las personas afectadas por la publicación puedan explicar errores en las mismas o inexactitudes. El inciso final del artículo $4^{\circ}$ señala: "A contar del día $1^{\circ}$ de enero del año 2010, las publicaciones de las aclaraciones de la nómina de deudores morosos, de los protestos de cheques, letras de cambios y pagarés, y de las letras de cambio y pagarés a las que se refiere la letra a) del numeral 6) del artículo 1, cuando aparecieren indudablemente pagadas, o cuando las obligaciones derivadas de tales documentos se hubieren extinguido de otro modo legal, se efectuarán sin costo alguno para los interesados, cualquiera sea su monto, debiendo la Cámara de comercio efectuar tales aclaraciones en base a la información que conforme al artículo 19 de la ley 19.628, le deben entregar los acreedores, pudiendo los interesados, en todo caso, solicitar siempre la aclaración".

b) Ley 19.628 sobre Protección de Datos de Carácter Personales. La Ley 19.628 sobre Protección de Datos de Carácter Personales publicada el 28 de agosto del año 1999 y modificada por última vez el 17 de febrero de 2012 por la Ley 20.575, regula en su Título III la utilización de datos personales relativos a obligaciones de carácter económico, financiero, bancario o comercial.

El artículo 17 de la Ley 19.628 permite que se comunique la información que verse sobre obligaciones de carácter económico, financiero, bancario o comercial, cuando éstas consten en letras de cambio y pagarés protestados; cheques protestados por falta de fondos; por haber sido girados contra cuenta corriente cerrada o por otra causa; como asimismo el incumplimiento de obligaciones derivadas de mutuos hipotecarios y de préstamos o créditos de bancos, sociedades financieras, administradoras de mutuos hipotecarios, cooperativas de ahorro y créditos, organismos públicos y empresas del Estado sometidas a la legislación común, y de sociedades administradoras de créditos otorgados para compra en casas comerciales.

No se permite informar aquellos créditos concedidos por el Instituto Nacional de Desarrollo Agropecuario a sus usuarios. Tampoco se podrá informar aquellas obligaciones de carácter económico, financiero, bancario o comercial en cuanto hayan sido repactadas, renegociadas o novadas, o éstas se encuentren con alguna modalidad pendiente. 
Queda expresamente prohibido comunicar la información relacionada con las deudas contraídas con empresas públicas o privadas que proporcionen servicios de electricidad, agua, teléfono y gas; además de las deudas contraídas con concesionarios de autopistas por el uso de su infraestructura.

Establece asimismo una prohibición especial de informar morosidades o protestos cuando éstas se hayan originado durante el período de cesantía que afecte al deudor.

Se entrega además la facultad al Presidente de la República, para que a través de Decreto Supremo determine qué otras obligaciones de dinero deberán ser comunicadas, debiendo siempre estar sustentadas en instrumentos de pago o de crédito válidamente emitidos, debiendo constar el consentimiento expreso del deudor u obligado al pago y su fecha de vencimiento.

De esta manera, la actual ley se refiere a la información sobre los incumplimientos del consumidor y no sobre su comportamiento positivo. Esto es así, ya que el texto vigente de la ley señala que sólo podrán comunicar incumplimientos, excluyendo la posibilidad de comunicar cumplimientos del deudor que den cuenta de su real estado de endeudamiento.

Es así, como queda excluido informar sobre otros datos relacionados al estado de solvencia del deudor, como créditos obtenidos, saldos de cuentas, activos patrimoniales, garantías, historial laboral etc., que pueden influir en la apreciación del nivel de endeudamiento y la solvencia del consumidor.

c) Ley 20.575, que establece el principio de finalidad en el tratamiento de datos personales. La Ley 20.575 tuvo como objetivo establecer el principio de finalidad en el tratamiento de datos personales. De esta manera, se busca otorgar protección a las personas, evitando que sus antecedentes comerciales sean utilizados para un fin distinto que el de la evaluación de riesgo en el proceso de otorgamiento de un crédito ${ }^{29}$.

Se estableció además que la comunicación de esta clase de datos sólo puede efectuarse al comercio establecido, para el proceso de crédito, y a las entidades que participen de la evaluación de riesgo comercial y para ese solo fin. Quedando expresamente prohibido exigir esta información en

${ }^{29}$ Conforme se puede leer del proyecto de ley y en especial de los antecedentes presentados en el primer trámite constitucional en la Cámara de Diputados, se señala que: "Es del caso que en la actualidad cerca de cuatro millones de personas se encuentran en los registros de DICOM por diversas circunstancias de atrasos, moras o incumplimientos comerciales. Lamentablemente un sistema que es indispensable para la adecuada marcha de la economía y facilitar el acceso al crédito, ha desviado el propósito para el cual fue creado: evaluar el riesgo en el proceso de crédito". 
procesos de selección de personal, admisión preescolar, escolar o educación superior, atención médica de urgencia o postulación a un cargo público ${ }^{30}$.

En su artículo $3^{031}$ se establecieron los principios de legitimidad, acceso y oposición, información, calidad de datos, finalidad, proporcionalidad, transparencia, no discriminación, limitación de uso y seguridad en el tratamiento de datos personales. Los responsables implementar dichos principios son las entidades que contengan banco de datos y los distribuidores de los registros o bancos de datos personales. Por su parte el juez deberá considerar si existió la debida diligencia en el tratamiento de datos personales. Debiendo el distribuidor o responsable de los registros o banco de datos probar ante el juez que dio cumplimiento a las obligaciones impuestas por el artículo $3^{\circ}$ y que actúo con la debida diligencia en el tratamiento de los datos respectivos.

La presente ley, además establece la obligación de designar a una persona natural encargada del tratamiento de datos, permitiendo así a los titulares de datos puedan acudir ante él para efectos de hacer efectivo los derechos que les reconoce la Ley No 19.628, sobre protección de la vida privada.

d) Proyecto que modifica la Ley 19.628 sobre protección de datos personales. Actualmente se discute en el Congreso un proyecto de ley que modifica de manera importante la actual normativa sobre protección de datos personales $^{32}$. No obstante, no introduce grandes cambios en relación al

${ }^{30} \mathrm{El}$ proyecto de ley pretendía en su artículo $2^{\circ}$ que la comunicación de esta clase de datos sólo pudiera efectuarse a entidades reguladas por la Superintendencia de Bancos e Instituciones Financieras y que participen de la evaluación de riesgo para el proceso de crédito, consagrando además la responsabilidad solidaria por el mal uso de la comunicación de los datos.

${ }^{31}$ Además, en el artículo $3^{\circ}$ obliga a los distribuidores de los registros o bancos de datos de carácter económico, financiero, bancario o comercial a contar con un sistema de registros del acceso y entrega de estos antecedentes, individualizando el nombre de quien los ha requerido, el motivo, la fecha y la hora de la solicitud, así como el responsable de la entrega o cesión de la información. Los titulares de la información comercial podrán además solicitar cada cuatro meses y en forma gratuita la información consignada en dicho sistema durante los últimos doce meses.

${ }^{32}$ Conforme se lee del proyecto de ley (Boletín No 11.144-07), el objetivo general del proyecto es "actualizar y modernizar el marco normativo e institucional con el propósito de establecer que el tratamiento de los datos personales de las personas naturales se realice con el consentimiento del titular de datos o en los casos que autorice la ley, reforzando la idea de que los datos personales deben estar bajo la esfera de control de su titular, favoreciendo su protección frente a toda intromisión de terceros y estableciendo las condiciones regulatorias bajo las cuales los terceros pueden efectuar legitimamente el tratamiento de tales datos, asegurando estándares de calidad, información, transparencia $y$ seguridad". 
tratamiento de datos financieros o comerciales que regula el artículo de 17 de la actual ley ${ }^{33}$.

Se pierde así una oportunidad para avanzar en el tratamiento de datos personales que permita a los proveedores financieros conocer el estado actual de endeudamiento del consumidor. Para evitar el sobreendeudamiento es necesario conocer el nivel de endeudamiento, permitiendo que los proveedores conozcan no solo el incumplimiento de sus obligaciones, sino que también aquellas obligaciones financieras actuales que no han sido incumplidas. Es decir, establecer la existencia de un sistema de información crediticia positivo y no sólo negativo como existe en la presente ley ${ }^{34}$.

De considerarse lo anterior, el mayor beneficiado sería el consumidor, permitiendo que gran parte de los consumidores que se encuentran en el mercado financiero informal pasen al formal. Por otra parte, la valoración de un incumplimiento determinado y aislado no sería sancionado por el proveedor, si éste tuviese los antecedentes históricos que den cuenta del buen comportamiento del cliente.

No obstante, lo anterior, la actual ley sí avanza de manera indirecta en el desarrollo de establecer un sistema de información crediticio que otorgue mayores garantías a los consumidores. Esto, porque a diferencia de la anterior modificación legal, que estableció ciertos principios ${ }^{35}$, el actual proyecto avanza en entregar una definición de cada uno de ellos, además de incorporar otros nuevos.

Estos nuevos principios conforme al artículo 3 del proyecto de ley serían los siguientes:

i) Principio de licitud del tratamiento: Este principio exige que los datos personales sólo pueden tratarse con el consentimiento de su titular o por disposición de la ley. Para avanzar en un sistema de información crediticia positivo, es fundamental que la ley autorice entregar informa-

${ }^{33}$ El proyecto de ley en su página 5 y 6 declara en este sentido lo siguiente: "Además, cabe señalar que este proyecto de ley no innova respecto de la regulación especifica y actualmente vigente, referida al tratamiento de los datos personales relativos a obligaciones de carácter económico, financiero, bancario o comercial, manteniendo integramente las normas contenidas en el Titulo III de la ley, salvo adecuaciones formales $y$ de referencia".

${ }^{34}$ Cabe destacar que recientemente se promulgó la Ley № 21.214 que modifica la Ley No 19.628 sobre protección de la vida privada, con el objeto de prohibir que se informe sobre las deudas contraídas para financiar la educación en cualquiera de sus niveles.

${ }^{35}$ Principios de legitimidad, acceso y oposición, información, calidad de datos, finalidad, proporcionalidad, transparencia, no discriminación, limitación de uso y seguridad en el tratamiento de datos personales. 
ción a las entidades financieras y casas comerciales, relacionado al buen comportamiento de sus clientes.

ii) Principio de finalidad. Los datos personales deben ser recolectados con fines específicos, explícitos y lícitos. El tratamiento de los datos personales debe limitarse al cumplimiento de estos fines. En aplicación de este principio, no se pueden tratar los datos personales con fines distintos a los informados al momento de la recolección, salvo que el titular otorgue nuevamente su consentimiento, los datos provengan de fuentes de acceso público o así lo disponga la ley.

iii) Principio de proporcionalidad. Los datos personales que se traten deben limitarse a aquellos que resulten necesarios en relación con los fines del tratamiento. Los datos personales deben ser conservados sólo por el período de tiempo que sea necesario para cumplir con los fines del tratamiento, luego de lo cual deben ser cancelados o anonimizados. Un período de tiempo mayor requiere autorización legal o consentimiento del titular.

iv) Principio de calidad. Los datos personales deben ser exactos y, si fuera necesario, completos y actuales, en relación con los fines del tratamiento.

v) Principio de responsabilidad. Quienes realicen tratamiento de los datos personales serán legalmente responsables del cumplimiento de los principios, obligaciones y deberes de conformidad a esta ley.

vi) Principio de seguridad. En el tratamiento de los datos personales se deben garantizar niveles adecuados de seguridad, protegiéndolos contra el tratamiento no autorizado, pérdida, filtración, destrucción o daño accidental y aplicando medidas técnicas u organizativas apropiadas.

vii) Principio de información. Las prácticas y políticas sobre el tratamiento de los datos personales deben estar permanentemente accesibles y a disposición de cualquier interesado de manera precisa, clara, inequívoca y gratuita.

El artículo 13 del proyecto de ley establece las excepciones al consentimiento, indicando que no se requiere el consentimiento del titular entre otros casos cuando el tratamiento esté referido a datos relativos a obligaciones de carácter económico, financiero, bancario o comercial y se realice de conformidad con las normas del Título III de la actual ley de protección de la vida privada.

Como ya se revisó, no es posible conforme al texto vigente de la ley, informar sobre otros créditos obtenidos y su debido cumplimiento, por lo tanto, no es viable bajo la actual legislación crear un sistema de información positivo, salvo que cada deudor manifieste su consentimiento expreso a que se informe de aquellos datos que den cuenta de su actual estado de solvencia, como otros créditos obtenidos, saldos de cuentas, activos patrimoniales, garantías, historial laboral etc.

Entre los aspectos positivos del proyecto de ley, cabe destacar la creación 
de la Agencia de protección de datos personales, dotando al sistema de una entidad que podrá controlar el cumplimiento de la ley, evitando así un uso distinto que el permitido ${ }^{36}$.

e) Proyecto de Ley que regula el tratamiento de la información sobre obligaciones de carácter financiero o crediticio. Este proyecto fue presentado el año $2011^{37}$ y se encuentra sin movimiento en el Congreso desde el año 2014. La iniciativa tiene por finalidad mejorar los sistemas de información crediticia, corrigiendo en parte el problema de asimetría de información que impacta en el desarrollo del mercado del crédito. Asimismo, se pretende solucionar el problema de selección adversa, que influye en ocasiones en un racionamiento excesivo del crédito. En este sentido, el proyecto busca proporcionar a los proveedores de crédito un análisis del comportamiento de pago de los deudores, contenido en los registros o sistemas de información crediticia.

Se declara, además, que, mejorar la calidad de la información, a través de datos libres de error, veraces, íntegros, completos y actualizados, favorece para que no se produzcan denegaciones injustificadas de un préstamo o el otorgamiento del préstamo sea de un mayor costo. Así, el principal eje de la iniciativa legal descansa en la necesidad de "...ampliar la información sobre obligaciones financieras que actualmente está disponible en el mercado para, por una parte, agregar información sobre el buen comportamiento de pago de las personas y su situación crediticia y, por la otra, incorporar a otros agentes de crédito como aportantes de información al sistema. Ello, a fin de que el sistema no solo refleje información negativa o deuda morosa, como lo hace actualmente, sino también información sobre el buen comportamiento de pago de las personas de manera que éstas puedan hacer uso de su capital reputacional y acceder en mejores condiciones al mercado del crédito ${ }^{38}$.

Esto último se lograría extendiendo el concepto de información co-

${ }^{36}$ En el momento de la redacción de este trabajo, se discute si debe ser una agencia de carácter autónomo y de dedicación exclusiva, o que dicha competencia recayese en el Consejo General de Transparencia.

${ }^{37}$ Boletín No 7886-03.

${ }^{38} \mathrm{El}$ proyecto además tiene los siguientes ejes (i) establecer una regulación orgánica y ordenada del sistema de información comercial e introducir mecanismos de control de calidad, seguridad y veracidad de los datos; (ii) dotar a una instancia administrativa de las facultades necesarias para regular y supervisar a los agentes del sistema en lo que dice relación particularmente con la continuidad y confiabilidad de éste, y (iii) reforzar los derechos de los titulares de los datos, entendiendo que éstos son los dueños de su propia información, regulando asimismo los procedimientos necesarios para que los titulares de datos de obligaciones crediticias puedan hacer valer sus derechos. 
mercial que se indica en la Ley No 19.628, incluyendo no sólo a la deuda morosa o protestada, sino también, y por los beneficios que ello conlleva, a la deuda vigente.

Además, se amplía el tipo de instituciones obligadas a informar, de manera de incluir al comercio y a otras entidades que prestan servicios financieros relevantes. Así las instituciones obligadas a entregar los datos de obligaciones económicas abarcarán a todos los proveedores de crédito con carteras de cierto tamaño, los notarios públicos, en relación con los documentos protestados, y la Tesorería General de la República, en lo que respecta a deudas tributarias demandadas.

Para el cumplimiento de lo anterior el Proyecto de Ley propone un esquema que es orgánico con el sistema actualmente vigente, consolidando en un solo organismo la recopilación de información comercial. Para cumplir con lo anterior, se crearía un sistema de obligaciones económicas, denominado como (SOE). De esta forma, el proyecto propone crear un sistema oficial, en el que se registrarán, en los términos y condiciones que se establecen en el proyecto, todos los datos de obligaciones económicas.

Se establece, por lo tanto, la obligación de informar de los acreedores al sistema de obligaciones económicas o crediticias que se describen en el proyecto, incluyendo información de deuda morosa y también de deuda al día, ésta última con el consentimiento de los titulares, sentándose en el proyecto de ley las directrices y principios que deben regir la remisión de la información al sistema.

Se destaca asimismo en el proyecto que el SOE deberá ordenar, sistematizar y filtrar la información a la que pueden acceder los usuarios y las empresas de distribución de información comercial, preocupándose que se respeten los derechos de los titulares de los datos, y siempre en la forma y condiciones permitidas por el proyecto de ley. En este sentido es destacable la existencia de un órgano central que se preocupe de resguardar los derechos de los deudores, en relación al uso de la información que realicen los acreedores.

De esta forma el administrador, quien será elegido luego de una licitación, deberá ser responsable de la base de datos, sometiéndose a los principios de tratamiento de datos personales expresados en la Ley No 19.628, dentro de los que destacan el principio de legitimidad, exactitud, finalidad, proporcionalidad, transparencia, no discriminación y seguridad en el tratamiento de los datos personales.

Por otra parte, el proyecto de ley tiene una especial preocupación por el resguardo de los datos personales de los consumidores y deudores, señalando que se requerirá el consentimiento del titular cuando: (i) se trate de información positiva o deuda vigente de ese titular, cualquiera 
sea el destinatario de esa información, esto es, sea o no agente crediticio; o (ii) se trate de información negativa que sea solicitada por una entidad distinta de los aportantes de información al sistema, categoría integrada básicamente por los proveedores de crédito, o en representación de éstos.

En esta misma línea, se establece que los titulares de los datos tendrán el derecho a ser informados sobre el propósito, contenido y destinatarios de los datos de obligaciones económicas que se refieran a ellos.

Para el correcto resguardo de los derechos de los titulares, el proyecto regula un procedimiento para rectificar y cancelar datos, que considera tres factores: a. El derecho del afectado de agregar una nota en el SOE de que el dato está siendo impugnado; b. En caso de error, se establece un procedimiento expedito para que todos los responsables de bases de datos donde figura la información rectifiquen el error, y c. Si el titular no queda conforme con la respuesta entregada puede recurrir al Servicio Nacional del Consumidor y a los tribunales de justicia.

Sobre el periodo de caducidad de la información, se establece que, tratándose tanto de obligaciones al día como de obligaciones morosas, la comunicación de los datos a terceros sólo podrá realizarse hasta cinco años después de la extinción total de la obligación o desde que ésta se hubiere hecho exigible. De esta forma el proyecto de ley no diferencia sobre el tipo de información (positiva o negativa) ni sobre el comportamiento de los titulares al establecer plazos de caducidad.

\section{Regulación comparada}

Con relación a la regulación existente en otros países, en los extremos se encuentra Francia con una prohibición de la actividad de los bureaus de crédito, ya que solo se permite el funcionamiento de un registro público de crédito ${ }^{39}$. En Francia no existe una base de datos única con toda la información crediticia tanto de personas físicas y jurídicas, sino que cohabitan ficheros diferentes: uno para personas físicas, otro para personas jurídicas y otro específico para cheques. El relativo a personas físicas, es un fichero que considera información relativa a préstamos concedidos para finalidades no profesionales ${ }^{40}$. En este fichero están obligados aportar información las entidades de crédito, sociedades de financiación, entidades de

${ }^{39}$ El registro público de solvencia (Service Central des Risques) se creó en 1946, a través de una decisión de carácter general del Consejo Nacional de Crédito de 7 de marzo de 1946, organizando la centralización de los riesgos bancarios (Décision de caráctere général du Conseil national du crédit du 7 mars 1946, organisant la centralisation des risques bancaires).

${ }^{40} \mathrm{Su}$ régimen legal está comprendido en los artículos 751 y 752 del Código de Consumo. 
moneda electrónica y entidades de pago, que son, asimismo, las únicas que pueden consultar el sistema de información. Para registrar la información se requiere que el incumplimiento de pago se deba a dos mensualidades de un crédito, cuando el plazo no es mensual y han pasado al menos 60 días desde que se debió realizar el pago, cuando la deuda es superior a 500 euros, cuando ha habido una denuncia de la mora en créditos sin pagos escalonados y también cuando en un procedimiento judicial se ha ordenado el vencimiento anticipado de la obligación. En todos estos casos, la entidad debe advertir al afectado la posibilidad de incluir sus datos en el fichero, dándole 30 días para regularizarla deuda. El periodo máximo de permanencia de los datos en el sistema de información es de cinco años desde el registro de datos ${ }^{41}$.

En el otro extremo en cambio se encuentran los países bajos, donde no existe referencia alguna en la ley de protección de datos del 6 de julio del año $2000^{42}$.

En aquellos países donde si existe regulación, como en el caso de Estados Unidos $^{43}$, Suecia, Finlandia, México, Ecuador y Perú, el marco regulatorio esta dado por una ley especial. En cambio, en otros países, como Italia ${ }^{44}$,

\footnotetext{
${ }^{41}$ Pascual Huerta, Pablo, Definición, cit. (n. 12) pp. 190-191.

${ }^{42}$ Boletín Oficial del Reino de los Países Bajos, 2000, 302, de 20 de julio de 2000.

${ }^{43}$ En Estados Unidos la regulación se encuentra en la "Fair Credit Reporting $A c t$ ", aprobada en el año 1970. Se trata de un instrumento legislativo que contiene herramientas de acción normativa del legislador federal sobre el mercado del "credit reporting". Se encuentra codificada en el United States Code (1681 y ss.) y coexiste con distintas leyes estatales sobre el mismo objeto, que prevalecen en el territorio de cada Estado, sobre la regulación federal.

${ }^{44}$ En Italia existe un registro público de solvencia desde el año 1962, el cual se gestiona por el Banco Central. Los bureau de crédito en Italia se encuentra regulados por una ley sectorial, en concreto en la ley de protección de datos personales. Si bien dicha normativa no tiene referencia alguna a los sistemas de información crediticia, la regulación especial se aprobó a través de Codice di deontología, que fue aprobado por la autoridad de protección de datos, a través de una resolución de 16 de noviembre de 2004, pasando a figurar como un anexo del Codice general de protección de datos.
} 
Alemania ${ }^{45}$ o España, la regulación se encuentra en uno o varios artículos de la ley general de protección de datos personales ${ }^{46}$.

En el marco europeo bajo el Reglamento de Protección de Datos, el cual entró en vigor en mayo del año 2018, no existe un tratamiento específico a los sistemas de información crediticia, puesto que no hay referencia alguna en dicho reglamento a la información crediticia. El cambio normativo europeo permite el tratamiento de datos personales siempre que dicho uso sea licito, abandonando la ley como fuente de licitud, es decir, no debe una ley permitir el uso de datos personales, bastando que su uso sea licito, debiendo eso si cumplir ciertos requisitos. En concreto, el artículo 6 del Reglamento Europeo señala en su apartado 1 que el tratamiento sólo será lícito si se cumple al menos una de las siguientes condiciones: a) El interesado dio su consentimiento para el tratamiento de sus datos personales para uno o varios fines específicos; $b$ ) el tratamiento es necesario para la ejecución de un contrato en el que el interesado es parte o para la aplicación a petición de este de medidas precontractuales; c) el tratamiento es necesario para el cumplimiento de una obligación legal aplicable al responsable del tratamiento; d) el tratamiento es necesario para proteger intereses vitales del interesado o de otra persona física; f) el tratamiento es necesario para la satisfacción de interés legítimos perseguidos por el responsable del tratamiento o por un tercero, siempre que sobre dichos intereses no prevalezcan los intereses o los derechos y libertades fundamentales del interesado que requieran la protección de datos personales, en particular cuando el interesado sea un niño.

En España ${ }^{47}$ la reciente ley de protección de datos personales de di-

${ }^{45}$ En Alemania funciona el registro público de crédito más antiguo dependiente de un banco central que fue creado en el año 1934 luego de las turbulencias financieras de la Gran Depresión. Si bien el registro siempre ha tenido una orientación hacia la supervisión del sistema financiero proporciona credit reports a los bancos que participan en el sistema, pero orientado a información de préstamos de importe superior al millón y medio de euros, por lo que el registro carece de influencia sobre el negocio minorista de la banca comercial del país. En Alemania son los bureaus de crédito los encargados de proporcionar información acerca del otorgamiento de créditos y de su incumplimiento. Desde el año 2009 se reformó la ley de protección de datos personales con el objetivo de regular los bureau de créditos. El objetivo principal de la reforma fue reforzar la transparencia de su funcionamiento, especialmente en todo lo relativo al credit scoring.

${ }^{46}$ Pascual Huerta, Pablo, Los ficheros, cit. (n. 22) pp. 336-337.

${ }^{47}$ En España en el mes el 6 de diciembre del año 2018 se publicó en el BOE la Ley Orgánica 3/2018 de Protección de Datos Personales y garantía de los derechos digitales. En la actual ley se mantiene la regulación general de protección de datos personales en el ámbito financiero, sin llegar a desarrollar un tratamiento específico al respecto. 
ciembre de 2018 regula en un solo artículo los sistemas de información crediticia, en concreto en el artículo 20, indicando en su apartado primero que: "Salvo prueba en contrario, se presumirá lícito el tratamiento de obligaciones dinerarias, financieras o de crédito por sistemas comunes de información crediticia cuando se cumplan los siguientes requisitos...".

Los requisitos exigidos son los siguientes: (i) Los datos deben haber sido facilitados por el acreedor o por quien actúe por su cuenta o interés. (ii) Los datos deben referirse a deudas ciertas, vencidas y exigibles, cuya existencia o cuantía no hubiese sido objeto de reclamación administrativa o judicial por el deudor o mediante un procedimiento alternativo de resolución de disputas vinculante entre las partes. (iii) El acreedor debe informar al afectado en el contrato o en el momento de requerir el pago acerca de la posibilidad de inclusión en dichos sistemas, con indicación de aquéllos en los que participe. (iv) Los datos sólo pueden mantenerse en el sistema mientras persista el incumplimiento, con el límite máximo de 5 años desde la fecha de vencimiento de la obligación dineraria, financiera o de crédito. (v) Los datos de un deudor determinado solo pueden ser consultados cuando quien consulte el sistema mantuviese una relación contractual con el afectado que implique el abono de una cuantía pecuniaria o este le hubiera solicitado la celebración de un contrato que suponga financiación, pago aplazado o facturación periódica, como sucede, entre otros supuestos, en los previstos en la legislación de contratos de crédito al consumo y de contratos de crédito inmobiliario.

Luego del cambio regulatorio en España, se puede constatar que no existe referencia a los datos de solvencia positivos, manteniéndose un tratamiento explícito a los antecedentes personales relativos al incumplimiento de obligaciones dinerarias, financieras o de crédito, es decir a los ficheros negativos ${ }^{48}$.

\section{SiSTEMAS DE INFORMACIÓN POSITIVOS Y NEGATIVOS}

\section{Importancia de un sistema de información mixto}

Los sistemas de información mixtos, es decir aquellos que están compuesto por datos que informan de las deudas cumplidas e incumplidas del deudor, son necesarios para prevenir el sobreendeudamiento y posterior insolvencia del consumidor. Como ya se ha podido advertir, un sistema que informa adecuadamente al proveedor financiero previene el riesgo de

${ }^{48}$ MAS BADIA, María Dolores, Los sistemas de información crediticia y la protección de datos personales: un reglamento europeo y una Ley Orgánica concebida y no nacida, en Actualidad Civil 5 (2018) p. 5. 
selección adversa, debido a las dificultades en escoger o valorar quién es buen pagador y quién no, que deriva en denegaciones de crédito injustificadas, o en aumentos generalizados del costo del crédito para salvaguardar el riesgo de impago ${ }^{49}$.

No existe a simple vista una justificación más allá de los intereses económicos de los proveedores financieros que les impida colaborar en la construcción de un sistema integrado, permitiendo así consolidar la información que de cuenta del comportamiento financiero del deudor.

Si bien es cierto que para permitir la circulación de información positiva es necesario el consentimiento previo del deudor, no existirían razones para que se negase a prestar su autorización, cuando será éste el principal beneficiado. Como ya hemos señalado, permitir que el acreedor conozca su comportamiento de pago le permitirá obtener créditos a un menor costo y para otros consumidores será fundamental para acceder a créditos que antes no le eran posibles.

Por otra parte, como ya adelantamos en el inicio de este trabajo, un SIC que entregue información relativa al oportuno pago del deudor, se constituiría como una valiosa herramienta al servicio del "préstamo responsable", cuyo núcleo se encuentra constituido en una parte importante por la obligación de evaluar la solvencia del deudor. Tal evaluación, solo puede realizarse de forma eficaz a partir de una información veraz, actualizada y lo más completa posible acerca de aquellos datos o factores que influyen o determinan la capacidad de pago del prestatario ${ }^{50}$.

La figura del préstamo responsable tiene así dos caras o propósito. El primero se relaciona con la idea de asegurar que el deudor tenga capacidad crediticia y puede asegurarse el efectivo pago de las obligaciones dinerarias que contraiga. El segundo propósito, es resguardar los intereses del consumidor y prevenir así que este caiga en insolvencia. En el ámbito europeo la obligación de evaluar la solvencia del deudor se regula por primera vez en el considerando 26 de la Directiva 2008/48/CE, bajo la idea de que "los prestamistas deben tener la responsabilidad de controlar individualmente la solvencia del consumidor" ${ }^{\prime 1}$. Luego se modifica por la Directiva 2014/17/

49 Como ha señalado Pascual Huerta, Pablo, Definición, cit. (n. 10) pp. 190-191. Sobre la importancia de un sistema mixto de información crediticio, se puede revisar el informe final evaluación del sistema de información comercial en Chile, en http://bibliotecadigital.dipres.gob.cl/bitstream/handle/11626/13729/ CLGroup_Evaluacion\%20Sistema\%20de\%20Informacion\%20Comercial\%20 en\%20Chile_2007.pdf;jsessionid=DA55685AB7BF5DC67C6AAC1F9A9B4CD7 ?sequence $=1$.

${ }^{50}$ Mas Badia, María Dolores, Los ficheros, cit. (n. 15) p. 12.

${ }^{51}$ En España la expresión "préstamo responsable” fue utilizada por primera vez en 
UE del Parlamento Europeo y del Consejo, de 4 de febrero de 2014, sobre los contratos de créditos celebrados con los consumidores para bienes inmuebles de uso residencial. Con referencia, en general a la obligación de evaluar la solvencia que pesa sobre el concedente del crédito, el art. 18 de la Directiva 2014/17/UE establece que: "Los Estados miembros velarán por que, antes de celebrar un contrato de crédito, el prestamista evalúe en profundidad la solvencia del consumidor. Dicha evaluación tendrá debidamente en cuenta los factores pertinentes para verificar las perspectivas de cumplimiento por el consumidor de sus obligaciones en virtud del contrato de crédito".

En Chile, sin embargo, no existe una normativa que imponga el deber de evaluar la solvencia del consumidor con el propósito de protegerle ante un posible estado de sobreendeudamiento o insolvencia. La única normativa que se observa, la cual se aloja en instrumentos administrativos como el Capítulo B-1 del Compendio de normas contables SBIF, tiene por finalidad resguardar su propia estabilidad patrimonial y, con ello, la del sistema financiero, respondiendo al modelo tradicional que impone la calificación de solvencia como un medio de control de las entidades financieras.

\section{Delimitación}

Se denomina sistemas de información crediticia (SIC), al conjunto de ficheros y base de datos que suministran información acerca de la solvencia de personas físicas o jurídicas, o por decirlo con mayor precisión la pluralidad de elementos, incluyendo a personas físicas o jurídicas, que están involucradas en el intercambio organizado de información a través de tecnologías avanzadas conforme a un procedimiento previamente acordados, con el propósito de recopilar, elaborar, compartir y/o suministrar información sobre solvencia de particulares y empresarios ${ }^{52}$.

Como ya hemos adelantado, los SIC pueden contener datos positivos y negativos del deudor. En el caso de Chile, los SIC por mandato legal solo pueden ofrecer información negativa. De esta manera, los datos relacionados al incumplimiento, si bien forman parte de la esfera de la intimidad del deudor, no ostentan una protección ilimitada, por lo que no existe

la ley 2/2011, de 4 de marzo, de Economía sostenible. En el artículo 29 denominado "Responsabilidad en el crédito y protección de los usuarios de servicios financieros". En los dos primeros apartados del art. 29.1 se recoge el deber de evaluar con la debida diligencia la solvencia del solicitante de crédito, resultan aplicables a cualquier prestatario potencia, no solo a los consumidores; abarca, por tanto, a los empresarios que soliciten crédito. En los siguientes se desarrolla una serie de exigencias que tienen como fin dotar de una protección reforzada a los consumidores de crédito”.

${ }^{52}$ Pascual Huerta, Pablo, Definición, cit. (n. 10) p. 122. 
un derecho absoluto a que se mantengan en reserva. Lo anterior, ya que la distribución de esta información cumple en el tráfico una importante función, permitiendo asegurar la estabilidad financiera del sistema.

Por su parte, para que exista información positiva del deudor, además de requerir una institucionalidad que lo regule y supervise permitiendo que los datos positivos del consumidor circulen libremente entre los proveedores financieros, es fundamental conforme a la actual ley de protección de datos personales que el deudor preste su consentimiento para que dicha circulación sea licita. De esta forma, conforme al estatuto jurídico actual, para que pueda existir en Chile un sistema de información positivo, es necesario que se establezca dicha posibilidad por ley, imponiendo el deber de compartir dichos datos a los proveedores de crédito cada vez que se autorice por el deudor.

Para cumplir con lo anterior, se debe generar mecanismos que permitan al consumidor declarar su disponibilidad a que su información positiva sea compartida, debiéndosele informar de las consecuencias legales y los beneficios que puede obtener si es que su comportamiento financiero tanto positivo como negativo está disponible en el sistema de información crediticio.

\section{Ventajas de un sistema de información positivo}

Permitir la circulación de datos positivos de los deudores favorece el desarrollo del sistema financiero. Primero, entregando estabilidad, ya que es posible advertir de mejor forma el riesgo cada vez que se concede un crédito, y además permite el ingreso de nuevos clientes al sistema ${ }^{53}$. Segundo, todo lo anterior favorece el desarrollo económico de un país,

${ }^{53}$ CuEna CASAS, Matilde, Ficheros de solvencia positivos, privacidad y mercado de crédito, en Cuena CaSAS, Matilde (directora), La prevención del Sobreendeudamiento Privado, Hacia un Préstamo y consumo responsable (Cizur Menor, Thomson Reuters Aranzadi, 2017) p. 310. Señala sobre las ventajas: “...Esta recomendación está avalada por el hecho de que, según avalan diversos estudios empíricos, los ficheros positivos incrementan el acceso al mercado de crédito con una disminución de los tipos de interés para los buenos pagadores. Suponen una herramienta para la prevención del sobreendeudamiento, disminuyen la tasa de incumplimiento, estimulan el préstamo responsable, favorecen la inclusión financiera por parte de aquellos deudores que pueden crear un historial crediticio que le permita el acceso al mercado en mejores condiciones e imponen a los deudores una disciplina de pago. Se trata de ventaja de gran impacto económico". Cabe destacar iniciativas privadas como www.destacame. cl que tienen como objetivo destacar a deudores de buen comportamiento y así mejorar su score crediticio, a través de la puntuación o buena evaluación entregada por distintos acreedores. 
puesto que transparenta el comportamiento, generando un círculo virtuoso de responsabilidad entre todos los actores participantes.

Otras de las principales ventajas que podemos destacar son las siguientes:

i) Inclusión financiera ${ }^{54}$ : En la línea de lo anterior, el efecto que produce compartir información financiera favorece al consumidor al facilitar el acceso a un crédito de menor costo y por ende favorece a aquellas personas de menos recursos y que por ende requieren de un producto financiero más económico para acceder a él. Lo anterior se cumple gracias a que el proveedor financiero si puede distinguir entre buenos y malos pagadores, podrá en definitiva diferenciar entre aquellos deudores que tienen un mayor riesgo de aquellos que tienen menos riesgo de incumplir el pago de su crédito. Si es posible evitar la selección adversa, las tasas de interés pueden fijarse a un menor valor, puesto que no será necesario determinar un riesgo promedio entre todos los clientes, sino que se podrá determinar en relación a un cliente determinado. Se evita así el indeseable efecto de que el crédito es demasiado alto para clientes de bajo riesgo y muy bajo para clientes de alto riesgo ${ }^{55}$. De esta forma, la inclusión financiera se produce dado que, si es posible discernir entre buenos y malos pagadores, la reacción no será la de no conceder un crédito a personas que deberían ser aceptadas, pero que en definitiva con un sistema imperfecto se les deniega, aumentando así la participación de personas en el sistema financiero formal ${ }^{56}$.

ii) Créditos de menor valor: Como ya se señaló, si es posible evitar conceder créditos a futuros incumplidores, la tasa de morosidad o incumplimiento disminuye, mejorando los indicadores del negocio financiero. Si lo comparamos con la producción de un servicio o producto, si estos tienen un menor valor de producción, dicho menor valor se traslada al precio final para el consumidor. Por lo tanto, el crédito será más barato si tiene un menor coste para el prestamista, puesto que no tendrá que internalizar en su negocio las pérdidas sufridas por el incumplimiento de algunos deudores.

iii) Disminuye la tasa de incumplimiento: El sistema es menos eficiente si no tienen todos los proveedores la posibilidad de conocer el historial crediticio de cada uno de los consumidores. Sólo algunos podrán advertir

\footnotetext{
${ }^{54}$ CARPI MARTÍn, Rebeca y FonT GORgORIÓ, Natalia, Ficheros de solvencia positiva y obligación de evaluación de la solvencia en España: retos pendientes en el mercado de crédito, en Actualidad Civil, 12 (2017) p. 5.

55 Turner, Michael y Varghese, Robin, Economic Impacts of Payment Reporting Participation in Latin America (2007). Disponible [en línea]: http://www.perc.net/ publications/economic-impacts-pay-ment-reporting-participation-latin-america, p. 4.

${ }^{56}$ Cuena Casas, Matilde, Ficheros, cit. (n. 53) p. 320.
} 
el riesgo de prestar dinero a un determinado deudor. En cambio, otros al no tener dicha información podrán conceder préstamos a deudores sobreendeudados que están al borde de la insolvencia. En caso de tener todos la misma información, se podrá evitar conceder créditos de riesgo y así disminuir la tasa de incumplimiento ${ }^{57}$.

iv) Aumenta la competencia entre oferentes: Esto se explica porque si los datos del cliente circulan, éste tendrá la posibilidad de que otras entidades de crédito conozcan su comportamiento y por ende esto facilita su cambio de entidad, ya que cualquiera de los proveedores que operan en el mercado puede acceder a un historial crediticio completo y así ofertar mejores condiciones de créditos a consumidores que no son sus clientes.

v) Previene el sobreendeudamiento: Los SIC que consideran información positiva se constituyen como un mecanismo eficaz para prevenir el sobreendeudamiento. CUENA CASAS ${ }^{58}$ lo explica muy bien al señalar: "Cuando un sistema sólo ofrece información negativa, excluye al deudor que ha incumplido del mercado, pero no al que no tiene dato negativo en su historial, pero no tiene deudas asumidas de cuya existencia no tenían conocimiento los prestamistas. Si para evaluar la solvencia del deudor éstos sólo tienen en cuenta sus ingresos, es obvio que la ratio de deuda asumida en su relación con los ingresos (debt to income) permanece opaca. Un sujeto con un salario de 3.000 euros al mes puede ser solvente con un SIC con datos negativos y sería insolvente con un sistema de información positiva dado que este último daría cuenta de las deudas asumidas, aunque todavía impagadas. En este sentido, los ficheros positivos excluyen del sistema al potencial deudor sobreendeudado y, por ello constituyen un instrumento para prevenir el sobreendeudamiento."

\section{Sistemas de información positivos y protección de datos personales}

Expuestas ya todas las ventajas de un sistema positivo de información crediticia, cabe analizar de qué forma se puede desarrollar un sistema de este tipo que no vulnere la protección de datos personales del consumidor. Ahora bien, en primer lugar, debemos dejar por sentado que la información crediticia negativa del deudor no le genera a éste ningún beneficio.

${ }^{57}$ Se puede revisar estudio empírico que toma muestras de países como Brasil y argentina en Majnoni, Giovanni; Miller, Margaret; Mylenko, Nataliya y Powell, Andrew, Improving Credit Information, Bank Regulation and Supervision: On the Role and Design of Public Credit Registries. Documento de trabajo sobre investigaciones relacionadas a políticas de desarrollo 3443 del Banco Mundial (2004) p. 33. Disponible [en línea]: https://elibrary.worldbank.org/doi/abs/10.1596/1813-94503443.

${ }^{58}$ Cuena Casas, Matilde, Ficheros, cit. (n. 53) p. 341. 
El SIC negativo existe para entregar estabilidad financiera y puedan así los proveedores discernir de un buen deudor de un mal deudor. Por el contrario, el beneficio de un SIC positivo como ya hemos fundamentado permite que el consumidor pueda obtener créditos en mejores condiciones e incluso acceder a créditos que sin un SIC positivo no podría obtener.

Determinado lo anterior, no existen razones para no avanzar en el establecimiento de un marco jurídico que permita la existencia de un SIC positivo. De esta manera, la regulación del sistema debería determinar qué datos se deben incluir para efectos de evaluar la solvencia del deudor. En este sentido, por ejemplo, podría ayudar incluir información relacionada a gastos básicos, como agua, luz, gas o telefonía, puesto que en el caso de consumidores de bajos ingresos, el cumplimiento de dichos pagos entrega información sobre el comportamiento del deudor. Asimismo, es necesario establecer mecanismos adecuados para garantizar que el uso de tales datos se realiza exclusivamente para el cumplimiento de dicha finalidad. El proyecto de ley que se discute actualmente en el congreso, relativo a la protección datos personales ${ }^{59}$, establece una agencia u organismo autónomo que velará por el cumplimiento de la normativa, por lo cual existiría un órgano con competencia en este ámbito. Además, es necesario resguardar la integridad de los datos, en el sentido de que éstos sean exactos y sobre todo que se encuentren actualizados. Deben asimismo especificarse de manera expresa quiénes son los proveedores de datos y las fuentes de información a la que pueden acceder los empresas comerciales o bureaus de crédito.

Establecido ciertos mecanismos adecuados que garanticen la protección de datos de los consumidores, es necesario determinar bajo qué supuestos pueden acceder los proveedores financieros y otros interesados a la información positiva del deudor. En este sentido, los sujetos que accedan al historial crediticio deben tener un propósito legítimo tipificado legalmente ${ }^{60}$. Por su parte, ya sea las entidades privadas o el ente público responsable de entregar la información, deben sujetarse a una regulación que sea por una parte clara y establezca sanciones en caso de incumplimiento. Sobre todo, en aquellos casos en que se facilite la información a sujetos que no tienen derecho a dicho acceso.

${ }^{59}$ Boletín No 11.144-07.

${ }^{60}$ Así lo hace la Fair Credit Reporting Act (FCRA) en EEUU (\& 604 (Tít 15 US Code $\& 1681 b)$, pudiendo acceder al informe crediticio las compañías aseguradoras, los sujetos que pretendan iniciar una operación de crédito con el titular de los datos, propietarios para evaluar la solvencia del potencial inquilino. También los empleadores pueden acceder al informe crediticio de los candidatos, previo consentimiento de éstos. Además, siempre cualquiera puede acceder al informe crediticio siempre que cuente con la autorización escrita del titular de los datos. 
Ahora bien, para el uso de la información positiva será siempre necesario establecer los criterios de legitimación en virtud del cual los proveedores de servicios de crédito podrán compartir voluntariamente información con empresas de información comercial.

En el ordenamiento constitucional chileno y en el derecho europeo, la regulación del derecho de protección de datos personales se erige como un derecho fundamental (artículo 19 No 4 de la Constitución Política de Chile), por lo cual resulta necesario el consentimiento del deudor para que se pueda acceder a su información de carácter personal, salvo que exista legitimación por parte de terceros para acceder a ella ${ }^{61}$.

Ahora bien, el consentimiento del deudor será necesario para puedan los terceros legitimados a acceder a la información. Es decir, no será necesario solicitar el consentimiento del deudor para recopilar sus datos positivos, sino que para que los terceros legitimados accedan a ellos. De lo contrario, sería inviable construir un SIC positivo, puesto que para que el mismo exista se requiere que la información esté disponible en una base de datos, permitiendo su acceso cada vez que el deudor lo autorice ${ }^{62}$.

${ }^{61}$ Chile desde el año 2018 a través de la Ley No 21.096 modificó su Constitución Política para incorporar la protección de datos en el número $4^{\circ}$ del artículo 19. Como señala BaUzÁ Martorell, Felio José, El modelo europeo de protección de datos. Experiencias para la regulación chilena y futura, en Ars Boni et Aequi, 15 (2019) 1, p. 123. [doi: http://dx.doi.org/10.23854/07192568.2019152Bauza121]: “...esta reforma tiene especial importancia porque hasta la fecha la Carta no contemplaba la protección de datos y a partir de su entrada en vigor esta materia se convierte en un derecho constitucional, remitiéndose a una norma con rango de ley para determinar la forma y condiciones de su tratamiento y protección”. No obstante luego señala que: "Esta legislación chilena fue pionera y como tal una de las primeras en América, latina sobre protección de datos personales, pero se aprobó con un contenido sensiblemente menor que el propio proyecto, por lo que adolece desde un primer momento de una serie de insuficiencias, por ejemplo, ausencia de sanciones efectivas, falta de regulación del flujo transfronterizos de datos personales, autorización del uso de datos para marketing directo sin consentimiento del titular, ausencia de una autoridad administrativa de control, excepciones amplias al consentimiento para el tratamiento de datos. Viollier Bonvin, Pablo, El Estado de la protección de datos personales en Chile. Disponible [en línea]: https://www.derechosdigitales.org/wpcontent/uploads/the-protection-of-personal-data-in-chile_c.pdf.

${ }^{62}$ Contreras Vásquez, Pablo y Trigo Kramcsák, Pablo, Interés legítimo y tratamiento de datos personales: Antecedentes comparados y regulación en Chile, en Revista Chilena de Derecho y Tecnología 8 (2019) 1, p. 70 se refieren al principio de licitud indicando que este "constituye el pilar fundamental sobre el que descansa el derecho de protección de datos personales. En virtud de este principio, el tratamiento de cualquier información concerniente a una persona natural solo puede tener lugar si concurre previamente el consentimiento del titular $\mathrm{u}$ otra fuente habilitante prevista por la ley. Las fuentes o bases de legitimidad son aquellas hipótesis definidas 


\section{Conclusiones}

i) El fenómeno del sobreendeudamiento requiere de mecanismos eficaces para prevenirlo, debiendo entregar el sistema jurídico herramientas que permitan al proveedor financiero evaluar de manera correcta el estado de deuda del consumidor.

ii) Los SIC abordan un problema fundamental de los mercados crediticios: la información asimétrica entre deudores y acreedores, que puede llevar a selección adversa, es decir, entregar créditos a deudores que se encuentran sobreendeudados, $y$, por ende, con posibilidades de caer en insolvencia.

iii) La existencia de SIC positivos resulta indispensable para la correcta evaluación de solvencia del deudor. Además, su existencia permitiría hacer posible la aplicación del principio "préstamo responsable", en virtud del cual se puede imponer el deber al proveedor financiero de evaluar la solvencia del deudor.

iv) El marco jurídico actual, que regula los SIC, es insuficiente para obtener un correcto control, calidad y veracidad de los datos, sin que exista hasta ahora una entidad especializada que supervise o monitoree el correcto funcionamiento de la industria, y en especial un adecuado tratamiento de los datos que administran.

v) Los principios generales que informan a un correcto SIC debiesen considerar las recomendaciones del Banco Mundial, es decir: integridad de datos; procesos, gobierno corporativo y gestión de riesgo; marco jurídico y reglamentario que resguarde debidamente derechos de consumidores; y flujos transfronterizos de datos.

vi) Conforme al actual normativa que regula los SIC, solo es posible informar sobre el incumplimiento o morosidad, sin que sea viable bajo la actual legislación crear un sistema de información positivo que entregue antecedentes completos sobre el comportamiento de pago del deudor.

vii) La existencia de un SIC positivo favorece el desarrollo del sistema financiero, entregando por una parte estabilidad, ya que permite advertir mejor el riesgo de incumplimiento, y por otra, permite el ingreso de nuevos consumidores al sistema, favoreciendo el desarrollo económico de un país.

viii) Exigir mayor responsabilidad a los proveedores financieros, en el sentido del deber de evaluar la solvencia de los deudores, es solo posible bajo la existencia de un SIC que entregue información exacta acerca del estado financiero de los consumidores, lo cual incluye información positiva y negativa.

legalmente y que, junto al consentimiento del titular, facultan el tratamiento de datos personales". 


\section{BiBLIOGRAFÍA}

Banco Mundial, General Principles for Credit Reporting (Washington DC, 2011). Disponible [en línea]: http://documents.worldbank.org/curated/ en/2011/09/16426885/general-principles-credit-reporting.

Bauzá Martorell, Felio José, El modelo europeo de protección de datos. Experiencias para la regulación chilena y futura, en Ars Boni et Aequi, 15 (2019) 1, pp. 121-148. [doi: http://dx.doi.org/10.23854/07192568.2019152Bauza121].

Bozzo Hauri, Sebastián, Sobreendeudamiento del consumidor en Chile: una revisión a la luz del derecho europeo, en Revista de Derecho (Valdivia), 33 (2020) 1, pp. 159183. [https://doi.org/10.4067/S0718-09502020000100159].

CARPI martín, Rebeca y Font Gorgorió, Natalia, Ficheros de solvencia positiva y obligación de evaluación de la solvencia en España: retos pendientes en el mercado de crédito, en Actualidad Civil, 12 (2017).

Caballero Germain, Guillermo, Sobreendeudamiento y exoneración legal de los saldos insolutos en el procedimiento concursal del consumidor, en Revista Ius et Praxis, 24 (2018) 3, pp. 135-139.

Comisión Europea. DG Mercado Interior y Servicios, Informe del Grupo de Expertos en Historia de Crédito (mayo 2009). Disponible [en línea]: https://europa. eu/rapid/press-release_IP-08-1286_en.htm?locale=FR.

Contreras Vásquez, Pablo y Trigo Kramcsák, Pablo, Interés legítimo y tratamiento de datos personales: Antecedentes comparados y regulación en Chile, en Revista Chilena de Derecho y Tecnología, 8 (2019) 1, pp. 69-106.

Corporación Financiera Internacional, Sistemas de información crediticia. Guía informativa (Washington, 2006). Disponible [en línea]: http://documentos. bancomundial.org/curated/es/122091468177562819/Sistemas-de-informacioncrediticia-guia-informativa.

Cuena Casas, Matilde, Ficheros de solvencia positivos, privacidad y mercado de crédito, en Cuena Casas, Matilde (directora), La prevención del Sobreendeudamiento Privado, Hacia un Préstamo y consumo responsable (Cizur Menor, Thomson Reuters Aranzadi, 2017) pp. 281-416.

CUENA CASAS, Matilde, El Sobreendeudamiento privado como causa de la crisis financiera y su necesario enfoque multidisciplinar, ahora, en Prats AlBEntosa, Lorenzo - CuENA Casas, Matilde (coordinadores), Préstamo Responsable y Ficheros de Solvencia (Cizur Menor, Aranzadi Thomson Reuters, 2014) pp. 27-92.

Gallego SÁnchez, Esperanza, La obligación de evaluar la solvencia del deudor: Consecuencias derivadas de su incumplimiento, ahora, en PrATs Albentosa, Lorenzo Cuena Casas, Matilde (coordinadores), Préstamo Responsable y Ficheros de Solvencia (Cizur Menor, Aranzadi Thomson Reuters, 2014) pp. 207- 242.

Goldenberg Serrano, Juan Luis, El sobreendeudamiento y los paradigmas del consumidor financiero responsable y del proveedor financiero profesional, en Revista Ius et Praxis 26 (2020) 1, pp. 1-22.

Hernández Sampieri, Roberto, Fernández Collado, Carlos y Baptista Lucio, Pilar, Metodología de la Investigación (5a edición, Méjico, McGraw-Hill, 2013).

Majnoni, Giovanni; Miller, Margaret; Mylenko, Nataliya y Powell, Andrew, Improving Credit Information, Bank Regulation and Supervision: On the Role and Design of Public Credit Registries. Documento de trabajo sobre investigaciones 
relacionadas a políticas de desarrollo 3443 del Banco Mundial (2004). Disponible [en línea]: https://elibrary.worldbank.org/doi/abs/10.1596/1813-9450-3443.

MAS BADIA, María Dolores, Los sistemas de información crediticia y la protección de datos personales: un reglamento europeo y una Ley Orgánica concebida y no nacida, en Actualidad Civil 5 (2018).

MAS BADIA, María Dolores, Los ficheros de solvencia patrimonial en la proyectada nueva Ley Orgánica de Protección de Datos de carácter personal. ¿Un avance o una oportunidad perdida?, en Actualidad Civil 11 (2017).

Miller, Margaret, Credit Reporting Systems Around the Globe: The State of The Art in Public and Private Credit Registries, ahora, en Miller, Margaret (editor), Credit reporting systems and the international economy (Cambridge-Massachussets, MIT Press, 2003).

MONTES, Fredes, Sistemas de información crediticia. Principios generales y marco internacional, ahora, en Prats Albentosa, Lorenzo - Cuena CASAS, Matilde (coordinadores), Préstamo Responsable y Ficheros de Solvencia (Cizur Menor, Aranzadi Thomson Reuters, 2014) pp. 245-308.

Pascual Huerta, Pablo, Definición, funciones y estructura de los sistemas de información crediticia. El impacto del reglamento general de protección de datos de la Unión Europea, ahora, en CuEna CASAS, Matilde (directora), La prevención del Sobreendeudamiento Privado, Hacia un Préstamo y consumo responsable (Cizur Menor, Thomson Reuters Aranzadi, 2017) pp. 121-252.

Pascual Huerta, Pablo, Los Ficheros de solvencia positivos. Una visión desde el derecho comparado, ahora, en Prats Albentosa, Lorenzo - Cuena Casas, Matilde (coordinadores), Préstamo Responsable y Ficheros de Solvencia (Cizur Menor, Aranzadi Thomson Reuters, 2014) pp. 309-360.

Ruz LÁrtiga, Gonzalo, Nuevo derecho concursal chileno I y II, (Santiago, Thomson Reuters 2017).

SERNAC, ¿Quéhacer si estás sobreendeudado?, Disponible [en línea]: https://www.sernac. $\mathrm{cl} /$ portal/618/w3-article-55112.html.

Superintendencia de Bancos e Instituciones Financieras, Informe de Endeudamiento de 2019. Disponible [en línea]: http://www.cmfchile.cl/portal/estadisticas/606/ articles-28149_recurso_1.pdf.

Superintendencia de Bancos e Instituciones Financieras, Informe de Endeudamiento de 2018. Disponible [en línea]: https://www.sbif.cl/sbifweb3/internet/archivos/ publicacion_12362.pdf.

Superintendencia de Bancos e Instituciones Financieras, Informe de Endeudamiento de 2017. Disponible [en línea]: https://www.sbif.cl/sbifweb3/internet/archivos/ publicacion_11891.pdf.

Superintendencia de Bancos e Instituciones Financieras, Informe de Endeudamiento de 2016. Disponible [en línea]: https://www.sbif.cl/sbifweb3/internet/archivos/ DISCURSOS_11422.pdf.

Turner, Michael y Varghese, Robin, Economic Impacts of Payment Reporting Participation in Latin America (2007). Disponible [en línea]: http://www.perc.net/ publications/economic-impacts-pay-ment-reporting-participation-latin-america.

Viollier Bonvin, Pablo, El Estado de la protección de datos personales en Chile. Disponible [en línea]: https://www.derechosdigitales.org/wp-content/uploads/ the-protection-of-personal-data-in-chile_c.pdf. 